\title{
Depression and the craniocervical junction; a look at the hemispheric model
}

\author{
Robert C Kessinger ${ }^{1 *}$, Trevor Qualls², John F Hart ${ }^{3}$, Michael F Anderson ${ }^{4}$, Henri J Dallies ${ }^{5}$, Jered M Wayland ${ }^{6}$ and Benjamin L Bradshaw $^{7}$
}

Correspondence: drk@drkessinger.com

\section{CrossMark \\ $\leftarrow$ Click for updates}

\author{
${ }^{1}$ Private practice, Rolla, Missouri, USA. \\ ${ }^{2}$ Private practice, Southaven, Mississippi, USA. \\ ${ }^{3}$ Private practice, Greenville, South Carolina, USA. \\ ${ }^{4}$ Private practice, Dallas, Georgia, USA. \\ ${ }^{5}$ Private practice, Hendersonville, North Carolina, USA. \\ ${ }^{6}$ Private practice, Cape Girardeau, Missouri, USA. \\ ${ }^{7}$ Private practice, Sumpter, South Carolina, USA.
}

\begin{abstract}
Background: Studies have supported a right left hemispheric bias in depression for over 3 decades. The purpose of this study was to assess the role of the craniocervical junction (CCJ) in depression and to evaluate possible hemispheric bias between right and left atlas laterality.

Methods: One hundred and four patients presenting in 5 different clinics completed the Goldberg Depression Scale. Subjects repeated these surveys following 6 weeks Knee Chest Upper Cervical Specific (KCUCS) technique focused on improving craniocervical junction alignment and function.

Results: Statistically significant improvements were found for both right and left laterality groups following 6 weeks care. Right atlas laterality group reported more symptoms of depression on the initial survey and responded more favorably to care.

Conclusion: The KCUCS technique was found to have improved depression symptoms. The findings appear to be consistent with the right left hemispheric bias model for depression. More studies are encouraged to further evaluate these observations and the role of the CCJ in symptoms of depression.

Keywords: Depression, Craniocervical Junction, Upper Cervical Chiropractic, Hemispheric Model, Atlas Laterality
\end{abstract}

\section{Background}

Somatosensory evoked potentials, transcranial magnetic stimulation measurements, blind spot mapping and electro myographic studies have been used to study the effect of chiropractic manipulation on brain function [1-7]. These studies have supported impact on brain function and indirectly suggest neuroplastic brain changes occur in the cerebellum, basal ganglia, prefrontal cortex as well as the primary motor \& primary sensory cortex. A couple case series have reported positive effects for the symptoms of depression following application of an upper cervical technique $[8,9]$.

Depression is one of the most common psychiatric disorders [10]. First line treatment for major depressive disorders (MDD) is antidepressant medication or evidence-based psychotherapy [11-13]. Less than $40 \%$ respond well to the initial treatment $[14,15]$. According to the National Institute of Mental Health [10], in 2017, there were an estimated 17.3 million adults in the United States who had had at least one major depressive episode, representing $7.1 \%$ of all adults. Females made up $8.7 \%$ of these cases while males compiled $5.3 \%$. The population with the highest incidence were ages 18-25 (13.1\%).

Depression is a heterogenous condition that doesn't lend itself to a simple model. It becomes more complicated when parsing out anxiety and other co-morbidities. Depression diagnosis is dependent upon subjective complaints. According to DSM-V Criteria for Major Depressive Disorder (MDD) [16] 
the individual must be experiencing at least five of eight defined symptoms during the same 2-week period and at least one of the symptoms should be either (1) depressed mood or (2) loss of interest or pleasure.

Electrophysiological studies, neuroimaging, and neuropsychiatric testing have given insight into subtypes of depression [17]. Electrophysiological and neuroimaging studies have supported a right-left hemispheric bias for over three decades, reinforcing a right prefrontal cortex (PFC) bias over a weaker performing left PFC [18]. In the approach/withdrawal model the left pole of the frontal lobe has been described as the approach side while the right pole is the withdrawal side. The balance of these two poles bring about balanced emotional cognitive function. Less input from a weaker functioning left PFC allows for more negative withdrawal behavior consistent with depression $[19,20]$.

The EEG alpha rhythm is inversely proportional to brain activity [21]. In a relaxed, wakeful state with eyes closed, alpha waves peak. Alpha waves decrease with an eye open alert subject. Alpha frequencies represent less activity in any given brain region and have been found inversely correlated with cerebral blood flow as measured by PET [17] and fMRI [22]. Many studies have found frontal alpha asymmetry (FAA) with weaker left prefrontal cortex (PFC) function in depression $[17,23-29]$. PET studies have found hypometabolism in the left PFC in depression [30,31]. A meta-analysis of restingstate $\mathrm{fMRI}$ supported decreased activity in the anterior cingulate, dorsolateral PFC, insula and superior temporal gyrus, predominantly left-sided reductions in depression [32].

Not all studies concur with FAA with right left hemispheric bias for depression. Vinne et al [33], performed a meta-analysis and found no consistencies when correlating FAA with depression. Bruder et al, [17] were more favorable toward FAA in their meta-analysis. Investigators have reported inconsistencies due to comorbidities found in depression. Anxiety is found in one third of depression cases [34]. Anxiety has been shown to confound EEG findings, neuroimaging and neuropsychiatric testing findings regarding the hemispheric model for depression. Comorbidities and diagnostic subtypes may provide context for FAA and neuroimaging inconsistencies found in depression [35].

Grajny K et al, found stroke lesions in the left dorsolateral prefrontal cortex (DLPFC) are associated with increased depression symptoms [36]. This is consistent with other investigators findings of post-stroke depression related to left frontal lesions [37-42]. Starkstein and Robinson found higher incidence and severity of depression related to the proximity of a brain lesionto the left frontal pole $[43,44]$. Non-stroke related damage to the left DLPFC has as well been reported withdepression [45-47].

Investigators have identified networks involved in depression. Alalade et al [48], found aberrant functional connectivity between the cerebellum and the cerebral cortex in several neural networks in patients with depression. They further noted the cerebellum-ventromedial PFC coupling related to cognitive function while the cerebellum-posterior cingulate cortex coupling related to emotion processing in geriatric depression. Others have found a role for the cerebellum in regulation of cognition and emotion [49-53]. While others have found a connection between cerebellum and depression $[54,55]$. There is an important connection in the network between the cerebellum and prefrontal cortex function as it relates to various psychosis such as schizophrenia, bipolar, and depression [56].

In the present study, the Goldberg Depression Scale (GDS) was used to score symptoms of depression. SF-36 short survey was performed for each case as a comparison to GDS. Data was separated into left and right atlas laterality as well as male and female.

\section{Purpose of the study}

The purpose of this study was to evaluate the $\mathrm{CCJ}$ in relation to depression with emphasis on the hemispheric model. This was attempted by comparing pre-adjustment GDS scores to 6 weeks post upper cervical chiropractic care(UCCC) GDS scores. Physical and mental composite scores were evaluated via SF-36 short survey to comparedepression symptoms to overall self-reported physical and mental well-being. We evaluated for hemispheric bias in the patient's prior to care and post UCCC regarding right versus left atlas laterality. This evaluation tested our theory that atlas laterality is related to hemispheric laterality to the extent that right atlas laterality may relate to poorer left PFC function andcorrection of right atlas laterality may improve left PFC function. If statistically significant improvements are found in the Goldberg Depression Scale, then care directed at the CCJ may be a complementary novel drug free approach of addressing symptoms of depression.

\section{Methods}

The practice-based study design was approved by the Institutional Review Board at Sherman College of Chiropractic. There were 104 participants (67 females and 37 males) in the study and all signed consent forms. Mean age for the patients was 45.1 years old (standard deviation=17.2)ranging from 8 to 77 years of age. Most patients ( $n=87$ of the 104) were younger than 60 years of age.

The study included all new patients entering any of the five participating clinics and who fit the criteria of consenting to the participation within a designated 8-month period. The five attending chiropractors (one per office) were trained in the knee chest upper cervical specific (KCUCS) chiropractic technique. The technique utilizes the Tytron infra-red scanning technology to assess upper cervical subluxation status on a visit to visit basis along with prone leg check analysis. A three view cervical $x$-ray series was performed on each case consisting of A-P open mouth full cervical, neutral lateral and base posterior views for the purpose of assessing alignment 
of the cranio-cervical junction. A knee chest solid head-piece table set at 14-degree angle was employed for the adjusting technique. The KCUCS is a high-velocity low-amplitude (HVLA) torque adjustment. All these procedures were consistent with training through KCUCS chiropractic technique [57].

Prior to the administration of KCUCS chiropractic technique each participant completed the GDS along with an SF-36 questionnaire. Both the Goldberg survey and SF-36 have shown good validity $[\mathbf{5 8}, \mathbf{5 9}]$. Aminpoor $\mathrm{H}$, et al, found validity and reliability for the GDS for both identifying and monitoring progress of depression [58]. The GDS has shown effectiveness in discriminating between symptoms of depression and anxiety [60]. The SF-36 is a self-reported survey reflecting overall physical and mental well-being [59]. KCUCS technique was provided for a 6-week period. There was an average of 11.9 office visitsper patient with each patient receiving an average of 2.0 upper cervical chiropractic adjustments throughout 6 weeks UCCC.

The GDS is an in-office screening test for depression. It contains 18 questions with a progressive scale $0-5$. Starting at 0 representing never experiencing the issue up to 5 indicating the issue is experienced very much. Each patient was instructed to respond 0 to 5 to quantify the level of problem they were having with any given issue covered within the 18 questions. A lower GDS score is consistent with less depression. Following are the GDS screening test scoring ranges: $0-9$ no depression likely $10-21$ possible symptoms that may be due to depression or other medical issues. 2235 mild to moderate depression. 36-53 moderate to severe depression 54 and up severely depressed [58].

The KCUCS chiropractic care provided for each subject followed the same protocol in each of the 5 clinics regarding Tytron infra-red scanning, prone leg check analysis, x-ray analysis and the knee chest adjustments administered [57]. The exception in patient care between the 5 clinics was in the rest time of between 20 to 60 minutes immediately following each upper cervical adjustment. Early pioneering researchers studying upper cervical chiropractic technique believed a rest period immediately following an upper cervical adjustment was essential for improved outcomes [61]. It is thought longer rest periods facilitate stability of the cranio-cervical junction. There are no current data to support the preference of rest period length other than clinical experience.

Atlas laterality was determined via A-P open mouth x-ray analysis. The A-P open mouth view was modified to include the full cervical spine. A 2-inch cork was placed between the upper and lower teeth to provide a consistent window in the $\mathrm{C} 0 / \mathrm{C} 1 / \mathrm{C} 2$ anatomy. A smaller modified cork was used for subjects who were unable to use the 2 -inch cork. An acceptable picture was described as the top teeth striking the top $1 / 3$ of atlas lateral mass. Three $x$-ray findings were used to determine atlas laterality. 1. Inter odontoid space size was analyzed with consideration of malformation of the dens relative to $\mathrm{C} 2$ body. With no or minimal malformation, laterality was considered the side of larger inter-odontoid space. 2 . The relative position of the internal atlas lateral mass compared with the anterior foramen magnum. The internal lateral mass side deviating further away from the anterior foramen magnum was considered the atlas laterality side. 3 . The lateral margin of $\mathrm{C} 1$ lateral mass relative to the lateral margin of $\mathrm{C} 2$ body. The $\mathrm{C} 1$ lateral mass that shows most laterality relative to $\mathrm{C} 2$ lateral body was considered the atlas laterality side. There was a priority hierarchyfor these three $x$-ray findings with the first criteria having highest priority. It was up to the individual physician to make the final decision on atlas laterality using these criteria.

The specific characteristics of the misalignment along with vectors used for adjusting were determined by the three view cervical $x$-ray series described above. Frequency of upper cervical chiropractic adjustments administered was determined by KCUCS technique pattern analysis using Tytron infra-red thermography as well as leg length equality examination. Following 6 weeks UCCC the patient was instructed to fill out the GDS and SF-36 survey prior to any care given on that office visit.

\section{Analysis}

Pre-adjustment Goldberg and SF-36 scores were compared to 6-week post application of an upper cervical technique using the paired $\mathrm{t}$ test. Data normality is assumed when samples are 30 or more (Devore and Peck) [62]. Left versus right atlas listing data were compared with the two-sample t test using the unequal variance option. Data were analyzed in Stata 12.1 (DataCorp, College Station, TX). Two-tailed p-values less than or equal to the conventional alpha level of 0.05 were considered statistically significant.

\section{Results}

Analysis of Goldberg scores revealed statistically significant improvements in symptoms of depression for both female and male patients following 6 weeks of UCCC $(p<0.001$; Table 1$)$. According to the GDS scoring system [57] the average female and male scores prior to UCCC placed them in the moderate to severe depression category. Following 6 weeks KCUCScare both female and male scores downgraded one level to the mild to moderate depression category. Assessment of symptoms of depression prior to and post UCCC was not different between female and male according to the GDS.

There was a statistically significant right atlas laterality $(n=49$, Goldberg $=42.0$, standard deviation $[S D]=19.2$ ) bias over left atlas laterality $(n=55$, Goldberg=34.7 SD=15.2) in increased reported symptoms of depression prior to care $(p=0.0357)$. There was a statistically significant right atlas laterality bias over left atlas laterality in reduction of symptoms of depression following 6-week UCCC (Table 4). Analysis of SF36 , for physical and mental composite scores (PCS and MCS) indicated that females responded better $(p<0.001)$ compared to males ( $p>0.05$; Tables 2 and 3. SF-36 (PCS and MCS) did 
Kessinger et al, Neuroscience Discovery 2020,

http://www.hoajonline.com/journals/pdf/2052-6946-8-1.pdf

doi: $10.7243 / 2052-6946-8-1$

Table 1. Goldberg scores by gender, mean (SD). A lower score is better than a higher score.

\begin{tabular}{lllll}
\hline Gender & N & Pre & Pose & P-value \\
\hline Female & 67 & $37.8(17.0)$ & $31.6(13.4)$ & $<0.001$ \\
Male & 37 & $38.7(18.5)$ & $32.4(14.3)$ & $<0.001$ \\
\hline
\end{tabular}

Table 2. SF-36 PCS scores by gender, mean (SD). A higher score is better than a lower score.

\begin{tabular}{lllll}
\hline Gender & N & Pre & Post & P-value \\
\hline Female & 59 & $38.5(10.2)$ & $42.6(11.5)$ & $<0.001$ \\
Male & 34 & $43.6(9.3)$ & $44.9(11.7)$ & 0.4 \\
\hline
\end{tabular}

Table 3. SF-36 MCS scores by gender, mean (SD). A higher score is better than a lower score.

\begin{tabular}{lllll}
\hline Gender & N & Pre & Post & P-value \\
\hline Female & 59 & $46.3(12.8)$ & $50.9(9.9)$ & $<0.001$ \\
Male & 34 & $48.2(12.3)$ & $49.1(11.1)$ & 0.7 \\
\hline
\end{tabular}

Table 4. Pre-adjustment SF-36 and GDS by atlas listing.

\begin{tabular}{lcllll}
\hline Survey & $\mathrm{n}$ & Left atlas(SD) & $\mathrm{n}$ & Right atlas (SD) & $\mathrm{p}$ \\
\hline GDS pre & 55 & $34.7(15.2)$ & 49 & $42.0(19.2)$ & 0.0357 \\
GDS post & 55 & $30.3(12.7)$ & 49 & $33.7(14.6)$ & \\
GDS improvement & & 4.4 & 49 & 8.3 & \\
PCS pre & 50 & $40.9(10.3)$ & 43 & $39.8(10.0)$ & 0.6032 \\
PCS post & 50 & $43.8(11.7)$ & 43 & $43.1(11.5)$ & \\
PCS improvement $(p)$ & & 2.9 & & 3.3 & \\
MCS pre & 50 & $47.9(11.2)$ & 43 & $45.9(14.2)$ & 0.4582 \\
MCS post & 50 & $51.6(8.9)$ & 43 & $48.7(11.8)$ & \\
MCS improvement $(p)$ & & 3.7 & & 2.8 & \\
\hline
\end{tabular}

not show preference in either pre or post care assessments regarding right and left laterality atlas.

For the SF-36, statistically significant improvements were observed for PCS and MCS in females but not males (Tables 2-3).

There was a statistically significant difference for GDS scores between left and right atlas listing, where right atlas had worse scores $(p=0.0357$, higher scores are worse than lower scores with the GDS survey, Table 4). Differences for the SF-36 (PCS and MCS) between left and right atlas listings were not statistically significant ( $p>0.05$, Table 4). The largest improvement between left versus right atlas adjustment was observed for GDS right atlas (8.3 for right versus 4.4 for left, Table 4).

\section{Discussion}

Two case series studies have reported positive response in symptoms of depression following the application of an upper cervical chiropractic technique [8,9]. Roth $L$ et al, found improvements when studying 6 participants with either mild to moderate anxiety or depression symptoms based on the Generalized Anxiety Disorders-7. Genthner GC et al, reached statistically significant improvements in reported symptoms of depression according to the Beck Depression Inventory II survey following application of an upper cervical technique. Other investigators have found improvements in the symptoms of depression following the application of an upper cervical technique [63].

In this report the investigators determined atlas laterality in each case by $\mathrm{x}$-ray analysis. A right atlas laterality bias was observed over left atlas lateralityregarding both more reported symptoms of depression prior to care and more reductions in depression following 6-weeks UCCC. These findings may be consistent with the right left hemispheric bias observed in depression.

Carrick found strong statistical significance in 500 subjects with HVLA cervical spine manipulation increasing contralateral cortical activity. This double-blind controlled study also established, with strong statistical significance, manipulation of the cervical spine with HVLA specifically changed only one cortical hemisphere [7]. Somatosensory evoked potential studies and TMS measurements support chiropractic manipulation influence of brain function [1-6]. Lelic $D$ et al [64], found through somatosensory evoked potential with dipole source localization, HVLA chiropractic manipulation changes sensorimotor integration by impacting function in the prefrontal cortex. Low force techniques were not found to have the same response. Subclinical neck pain patients have demonstrated aberrant patterns of cerebellum inhibition (CBI) when studied via transcranial magnetic stimulation. Following chiropractic manipulation, these patients experienced changes in their CBI pattern which appeared like healthy controls $[2,4]$.

We found statistical significance for improvements in both symptoms of depression via GDS and overall physical and mental well-being via SF-36 short survey following 6 weeks upper cervical chiropractic care. The exception was forSF-36 MCS with men's right atlas laterality group. They did not reach statistical significance. We did not find right atlas laterality bias for SF-36 (PCS and MCS) in assessments prior to care or post UCCC as found in GDS. There was no consistency between pre and post care regarding female and male comparing GDS and SF-36 (PCS and MCS). Women responded more favorably than men in all measures of selfreported SF-36 physical and mental well-being following care. Women self-reported lower scores for SF-36 physical and mental well-being prior to care. The inconsistencies between GDS and SF-36 (PCS and MCS) may support a more specific association between right atlas laterality bias and the right left hemispheric bias model for depression. Findings for improvements in symptoms of depression following 6 weeks UCCC may not have been related to an overall sense of physical and mental well-being perceived by the patients.

Anxiety is a comorbidity that may confound the right left hemispheric bias observed in depression $[17,34,35]$. GDS has 
demonstrated the ability to differentiate symptoms of anxiety from depression [60]. Reducing the influence of anxiety when evaluating symptoms of depression may reflect a picture less encumbered with comorbidities. The use of GDS may be a factor for our findings more strongly aligning with the right left hemispheric bias in depression for right atlas laterality pre and post KCUCS technique.

Huang $M$ et al, found autonomic dysfunction affects risks of depression [65]. There is a large body of evidence relating reductions in heart rate variability with psychiatric disorders, including depression, schizophrenia and anxiety disorders [66-68]. Schumann A et al [69], included heart rate variability, blood pressure variability, baroflex sensitivity, respiration, skin conductance as well as the calculation of pupillary diameter and unrest index in their assessment of autonomic function in regard to major depression. They found consistency for sympathetic dominance in major depression. Kessinger et al [70], reported improvements in patients with elevated pulse pressure following the application of the KCUCS upper cervical technique. They suggested improved autonomic function, reduction in sympathetic dominance, as the most plausible explanation for pulse pressure reductions. Other investigators have found improvement in autonomic balance following the application of an upper cervical technique [71-79].

Improved autonomic function has been shown to improve symptoms of depression. Vagal activation is used as a method for the treatment of more severe cases of depression [80-82]. George MS et al, found vagus nerve stimulation improves mood disorders [83]. Vagal activation has as well been linked to improved immune system function [84]. Psychological stress, a well-known promotor of mood disorders, is capable of activating proinflammatory signaling molecules, including nuclear factor kappa B via activation of the sympathetic nervous system [85]. Other investigators have found links to the gut brain axis, the immune system and depression [86]. In this study the left atlas laterality group as well achieved statistical significance in improvements of depression symptoms following 6 weeks UCCC even though not to the level experienced by the right atlas laterality group. Improved autonomic function may provide a mechanism for findings of both left and right atlas laterality group that is outside of the right left hemispheric bias model for depression. There may be more variables regarding comorbidities and subtypes, autonomic and/or immune function issues that may explain results observed.

\section{Conclusion}

In this study the KCUCS technique was employed for the purpose of improving CCJ alignment. We have found statistical significance for improvement of the symptoms of depression following the application of the KCUCS technique. There was right atlas laterality bias for both reported depression symptoms as well as response to care drawing a possible connection to the right left hemispheric bias model for depression. Left PFC function may be negatively impacted by right atlas laterality and improved left PFC function may occur following the correction of right atlas laterality via UCCC. These findings are intriguing but not conclusive. Limitations for this study include the case series format and we did not employ EEG, neuroimaging or neuropsychiatric testing but relied on a standardized questionnaire to evaluate symptoms of depression pre and post care. This study is not meant to be conclusive regarding application of an upper cervical chiropractic technique and the resolution of depression. It will hopefully serve to motivate other investigators to evaluate the role of the $\mathrm{CCJ}$ in relation to the symptoms of depression. A proposed follow-up study may include electrophysiology testing, neuroimaging and/or neuropsychiatric testing in conjunction autonomic function analysis before and after the application of an upper cervical technique.

\section{List of abbreviation}

CCJ: Craniocervical junction

GDS: Goldberg Depression Scale

KCUCS: Knee chest upper cervical specific

UCCC: Upper cervical chiropractic care

MDD: Major depressive disorder

PFC: Prefrontal cortex

FAA: Frontal alpha asymmetry

DLPFC: Dorsolateral prefrontal cortex

HVLA: High velocity low amplitude

PCS: Physical composite score

MCS: Mental composite score

CBI: Cerebellum inhibition

\section{Competing interests}

The authors declare that they have no competing interests.

Authors' contributions

\begin{tabular}{|l|c|c|c|c|c|c|c|}
\hline Authors' contributions & RCK & TQ & JFH & MFA & HJD & JMW & BLB \\
\hline Research concept and design & $\checkmark$ & -- & -- & -- & -- & -- & -- \\
\hline Collection and/or assembly of data & $\checkmark$ & $\checkmark$ & $\checkmark$ & $\checkmark$ & $\checkmark$ & $\checkmark$ & $\checkmark$ \\
\hline Data analysis and interpretation & $\checkmark$ & -- & $\checkmark$ & -- & -- & -- & -- \\
\hline Writing the article & $\checkmark$ & -- & -- & -- & -- & -- & -- \\
\hline Critical revision of the article & $\checkmark$ & -- & $\checkmark$ & -- & -- & -- & -- \\
\hline Final approval of article & $\checkmark$ & $\checkmark$ & $\checkmark$ & $\checkmark$ & $\checkmark$ & $\checkmark$ & $\checkmark$ \\
\hline Statistical analysis & $\checkmark$ & -- & $\checkmark$ & -- & -- & -- & -- \\
\hline
\end{tabular}


Kessinger et al, Neuroscience Discovery 2020,

\section{Publication history}

Senior Editor: Thomas Müller, Alexianer St. Joseph-Krankenhaus Berlin-Weissensee, Germany.

Received: 13-Dec-2019 Final Revised: 08-Feb-2020

Accepted: 22-Feb-2020 Published: 12-Mar-2020

\section{References}

1. Haavik $\mathrm{H}$ and Murphy $\mathrm{B}$. The role of spinal manipulation in addressing disordered sensorimotor integration and altered motor control. $J$ Electromyogr Kinesiol. 2012; 22:768-76. | Article | PubMed

2. Daligadu J, Haavik H, Yielder PC, Baarbe J and Murphy B. Alterations in cortical and cerebellar motor processing in subclinical neck pain patients following spinal manipulation. J Manipulative Physiol Ther. 2013; 36:527-37. | Article | PubMed

3. Haavik-Taylor $\mathrm{H}$ and Murphy B. Cervical spine manipulation alters sensorimotor integration: a somatosensory evoked potential study. Clin Neurophysiol. 2007; 118:391-402. | Article | PubMed

4. Haavik-Taylor $\mathrm{H}$ and Murphy B. Transient modulation of intracortical inhibition following spinal manipulation. Chiropractic Journal of Australia. 2007; 37:106-116.

5. Taylor $\mathrm{HH}$ and Murphy B. Altered sensorimotor integration with cervical spine manipulation. J Manipulative Physiol Ther. 2008; 31:115-26. I Article | PubMed

6. Taylor $\mathrm{HH}$ and Murphy B. Altered central integration of dual somatosensory input after cervical spine manipulation. J Manipulative Physiol Ther. 2010; 33:178-88. | Article | PubMed

7. Carrick FR. Changes in brain function after manipulation of the cervical spine. J Manipulative Physiol Ther. 1997; 20:529-45. | PubMed

8. Roth L, Zelman D, Clum L and Roth J. Upper cervical care as a complimentary strategy for depression and anxiety: A prospective case series analysis. JUCCR. 2013; 49-59.

9. Genthner GC, Friedman HL and Studley CF. Improvement in depression following reduction of upper cervical vertebral subluxation using orthospinology technique. JVSR.

10. National Institute of Mental Health. Major depression. I Website

11. American Psychiatric Association. Diagnostic and Statistical Manual of Mental Disorders. 4. Washington, DC: American Psychiatric Association. 2000.

12. Kennedy SH, Lam RW, Parikh SV, Patten SB and Ravindran AV. Canadian Network for Mood and Anxiety Treatments (CANMAT) clinical guidelines for the management of major depressive disorder in adults. Introduction. J Affect Disord. 2009; 117 Suppl 1:S1-2. | Article | PubMed

13. American Psychiatric Association. Treating Major Depressive Disorder: A Quick Reference Guide. Washington, DC: American Psychiatric Association. 2010; 1-28.

14. Gaynes BN, Warden D, Trivedi MH, Wisniewski SR, Fava M and Rush AJ. What did STAR*D teach us? Results from a large-scale, practical, clinical trial for patients with depression. Psychiatr Serv. 2009; 60:1439-45. | Article | PubMed

15. Holtzheimer PE and Mayberg HS. Stuck in a rut: rethinking depression and its treatment. Trends Neurosci. 2011; 34:1-9. | Article | PubMed Abstract | PubMed FullText

16. American Psychiatric Association. Diagnostic and statistical manual of mental disorders (5th ed.). Washington, DC. 2013.

17. Bruder GE, Stewart JW and McGrath PJ. Right brain, left brain in depressive disorders: Clinical and theoretical implications of behavioral, electrophysiological and neuroimaging findings. Neurosci Biobehav Rev. 2017; 78:178-191. | Article | PubMed

18. Henriques JB and Davidson RJ. Left frontal hypoactivation in depression. J Abnorm Psychol. 1991; 100:535-45. | Article | PubMed

19. Davidson RJ, Marshall JR, Tomarken AJ and Henriques JB. While a phobic waits: regional brain electrical and autonomic activity in social phobics during anticipation of public speaking. Biol Psychiatry. 2000; 47:85-95. | Article I PubMed

20. Spielberg JM, Stewart JL, Levin RL, Miller GA and Heller W. Prefrontal Cortex, Emotion, and Approach/Withdrawal Motivation. Soc Personal Psychol Compass. 2008; 2:135-153. | Article | PubMed Abstract | PubMed FullText

21. Cook IA, O'Hara R, Uijtdehaage SH, Mandelkern M and Leuchter AF. Assessing the accuracy of topographic EEG mapping for determining local brain function. Electroencephalogr Clin Neurophysiol. 1998; 107:408-14. | Article | PubMed

22. Laufs H, Kleinschmidt A, Beyerle A, Eger E, Salek-Haddadi A, Preibisch $\mathrm{C}$ and Krakow K. EEG-correlated $\mathrm{fMRI}$ of human alpha activity. Neuroimage. 2003; 19:1463-76. | Article | PubMed

23. Allen JJ, Urry HL, Hitt SK and Coan JA. The stability of resting frontal electroencephalographic asymmetry in depression. Psychophysiology. 2004; 41:269-80. | Article | PubMed

24. Brzezicka A, Kaminski J, Kaminska OK, Wolynczyk-Gmaj D and Sedek G. Frontal EEG alpha band asymmetry as a predictor of reasoning deficiency in depressed people. Cogn Emot. 2017; 31:868-878. | Article I PubMed

25. Henriques JB and Davidson RJ. Left frontal hypoactivation in depression. J Abnorm Psychol. 1991; 100:535-45. | Article | PubMed

26. Kemp AH, Griffiths K, Felmingham KL, Shankman SA, Drinkenburg W, Arns $\mathrm{M}, \mathrm{Clark} C R$ and Bryant RA. Disorder specificity despite comorbidity: resting EEG alpha asymmetry in major depressive disorder and posttraumatic stress disorder. Biol Psychol. 2010; 85:350-4. | Article | PubMed

27. Mennella R, Messerotti Benvenuti S, Buodo G and Palomba D. Emotional modulation of alpha asymmetry in dysphoria: results from an emotional imagery task. Int J Psychophysiol. 2015; 97:113-9. | Article | PubMed

28. Stewart JL, Bismark AW, Towers DN, Coan JA and Allen JJ. Resting frontal EEG asymmetry as an endophenotype for depression risk: sex-specific patterns of frontal brain asymmetry. J Abnorm Psychol. 2010; 119:50212. | Article | PubMed Abstract | PubMed FullText

29. Feldmann L, Piechaczek CE, Grunewald BD, Pehl V, Bartling J, Frey $M$, Schulte-Korne $G$ and Greimel E. Resting frontal EEG asymmetry in adolescents with major depression: Impact of disease state and comorbid anxiety disorder. Clin Neurophysiol. 2018; 129:2577-2585. | Article | PubMed

30. Baxter LR, Jr., Phelps ME, Mazziotta JC, Schwartz JM, Gerner RH, Selin CE and Sumida RM. Cerebral metabolic rates for glucose in mood disorders. Studies with positron emission tomography and fluorodeoxyglucose $\mathrm{F}$ 18. Arch Gen Psychiatry. 1985; 42:441-7. | Article | PubMed

31. Bench CJ, Friston KJ, Brown RG, Frackowiak RS and Dolan RJ. Regional cerebral blood flow in depression measured by positron emission tomography: the relationship with clinical dimensions. Psychol Med. 1993; 23:579-90. | Article | PubMed

32. Fitzgerald PB, Laird AR, Maller J and Daskalakis ZJ. A meta-analytic study of changes in brain activation in depression. Hum Brain Mapp. 2008; 29:683-95. | Article | PubMed Abstract | PubMed FullText

33. van der Vinne $N$, Vollebregt MA, van Putten $M$ and Arns $M$. Frontal alpha asymmetry as a diagnostic marker in depression: Fact or fiction? A meta-analysis. Neuroimage Clin. 2017; 16:79-87. | Article | PubMed Abstract I PubMed FullText

34. Hasin DS, Goodwin RD, Stinson FS and Grant BF. Epidemiology of major depressive disorder. Arch Gen Psychiatry. 2006; 62:1097-1106.

35. Fountoulakis KN, Lacovides A, Gerasimou G, Fotiou F, Loannidou C, Bascialla F, Grammaticos $P$ and Kaprinis $G$. The relationship of reciprocal regional cerebral blood flow with subtypes of major depression. Biol. Psychiatry. 2004; 28:537-546.

36. Grajny K, Pyata H, Spiegel K, Lacey EH, Xing S, Brophy C and Turkeltaub PE. Depression Symptoms in Chronic Left Hemisphere Stroke Are Related to Dorsolateral Prefrontal Cortex Damage. J Neuropsychiatry Clin Neurosci. 2016; 28:292-298. | Article I PubMed 
37. Hama S, Yamashita H, Shigenobu M, Watanabe A, Kurisu K, Yamawaki S and Kitaoka T. Post-stroke affective or apathetic depression and lesion location: left frontal lobe and bilateral basal ganglia. Eur Arch Psychiatry Clin Neurosci. 2007; 257:149-52. I Article I PubMed

38. Tang WK, Lu JY, Chen YK, Chu WC, Mok V, Ungvari GS and Wong KS. Association of frontal subcortical circuits infarcts in poststroke depression: a magnetic resonance imaging study of 591 Chinese patients with ischemic stroke. J Geriatr Psychiatry Neurol. 2011; 24:44-9. | Article | PubMed

39. Robinson RG, Kubos KL, Starr LB, Rao K and Price TR. Mood disorders in stroke patients. Importance of location of lesion. Brain. 1984; 107 ( Pt 1):81-93. | Article | PubMed

40. Herrmann M, Bartels $C$ and Wallesch CW. Depression in acute and chronic aphasia: symptoms, pathoanatomical-clinical correlations and functional implications. J Neurol Neurosurg Psychiatry. 1993; 56:672-8. Article | PubMed Abstract | PubMed FullText

41. Parikh RM, Lipsey JR, Robinson RG and Price TR. Two-year longitudinal study of post-stroke mood disorders: dynamic changes in correlates of depression at one and two years. Stroke. 1987; 18:579-84. | Article | PubMed

42. Iacoboni M, Padovani A, Di Piero V and Lenzi GL. Post-stroke depression: relationships with morphological damage and cognition over time. Ital J Neurol Sci. 1995; 16:209-16. | Article | PubMed

43. Starkstein SE and Robinson RG. Lateralized emotional response following stroke. In: M. Kinsbourne, Editor, Cerebral Hemisphere Function in Depression, American Psychiatric Press, Washington D.C. 1988; 25-47.

44. Rotenberg VS. The peculiarity of the right-hemisphere function in depression: solving the paradoxes. Prog Neuropsychopharmacol Biol Psychiatry. 2004; 28:1-13. | Article | PubMed

45. Thomas AJ, Perry R, Kalaria RN, Oakley A, McMeekin W and O'Brien JT. Neuropathological evidence for ischemia in the white matter of the dorsolateral prefrontal cortex in late-life depression. Int J Geriatr Psychiatry. 2003; 18:7-13. I Article | PubMed

46. Fedoroff JP, Starkstein SE, Forrester AW, Geisler FH, Jorge RE, Arndt SV and Robinson RG. Depression in patients with acute traumatic brain injury. Am J Psychiatry. 1992; 149:918-23. I Article I PubMed

47. Koenigs M, Huey ED, Calamia M, Raymont V, Tranel D and Grafman $J$. Distinct regions of prefrontal cortex mediate resistance and vulnerability to depression. J Neurosci. 2008; 28:12341-8. | Article | PubMed Abstract | PubMed FullText

48. Alalade E, Denny K, Potter G, Steffens D and Wang L. Altered cerebellarcerebral functional connectivity in geriatric depression. PLoS One. 2011; 6:e20035. | Article | PubMed Abstract | PubMed FullText

49. Schmahmann JD and Sherman JC. The cerebellar cognitive affective syndrome. Brain. 1998; 121 ( Pt 4):561-79. | Article | PubMed

50. Schmahmann J. The role of the cerebellum in affect and psychosis. Journal of Neurolinguistics. 2000; 13:189-214.

51. Schmahmann JD. The role of the cerebellum in cognition and emotion: personal reflections since 1982 on the dysmetria of thought hypothesis, and its historical evolution from theory to therapy. Neuropsychol Rev. 2010; 20:236-60. I Article I PubMed

52. Stoodley CJ. The cerebellum and cognition: evidence from functional imaging studies. Cerebellum. 2012; 11:352-65. | Article | PubMed

53. Middleton FA and Strick PL. Anatomical evidence for cerebellar and basal ganglia involvement in higher cognitive function. Science. 1994; 266:458-61. | Article | PubMed

54. Fitzgerald PB, Laird AR, Maller J and Daskalakis ZJ. A meta-analytic study of changes in brain activation in depression. Hum Brain Mapp. 2008; 29:683-95. | Article | PubMed Abstract | PubMed FullText

55. Konarski JZ, Mclntyre RS, Grupp LA and Kennedy SH. Is the cerebellum relevant in the circuitry of neuropsychiatric disorders? J Psychiatry Neurosci. 2005; 30:178-86. | Article | PubMed Abstract | PubMed FullText

56. Phillips JR, Hewedi DH, Eissa AM and Moustafa AA. The cerebellum and psychiatric disorders. Front Public Health. 2015; 3:66. I Article I PubMed $\underline{\text { Abstract | PubMed FullText }}$

57. Knee Chest Upper Cervical Specific. | Website

58. Hassan Aminpoor, Jafar Afshinfar, Ali Mostafaei and Shahla Ostovar. Validation of Goldberg's Depression Scale in academic and nonacademic peoples. Annals of Biological Research. 2012; 3:4564-4573.

59. Zhang Y, Qu B, Lun SS, Guo Y and Liu J. The 36-item short form health survey: reliability and validity in Chinese medical students. Int J Med Sci. 2012; 9:521-6. | Article | PubMed Abstract | PubMed FullText

60. Monton C, Perez Echeverria MJ, Campos R, Garcia Campayo J and Lobo A. [Anxiety scales and Goldberg's depression: an efficient interview guide for the detection of psychologic distress]. Aten Primaria. 1993; 12:345-9. I PubMed

61. Palmer BJ. Chiropractic clinical controlled research. XXV. W.B. Conkey Company; Hammond, Indiana. 1951.

62. Devore J and Peck R. Statistics: The exploration and analysis of data. Pacific Grove, CA: Duxbury. 4th Edition. 2001; 410.

63. Desaulniers AMJ. Effect of subluxation-based chiropractic care on quality of life in a patient with major depression. $J$ Vert Sublux Res. 2008; 1:1-7.

64. Lelic D, Niazi IK, Holt K, Jochumsen M, Dremstrup K, Yielder P, Murphy B, Drewes AM and Haavik H. Manipulation of Dysfunctional Spinal Joints Affects Sensorimotor Integration in the Prefrontal Cortex: A Brain Source Localization Study. Neural Plast. 2016; 2016:3704964. I Article I PubMed Abstract | PubMed FullText

65. Huang M, Shah A, Su S, Goldberg J, Lampert RJ, Levantsevych OM, Shallenberger L, Pimple P, Bremner JD and Vaccarino V. Association of Depressive Symptoms and Heart Rate Variability in Vietnam War-Era Twins: A Longitudinal Twin Difference Study. JAMA Psychiatry. 2018; 75:705-712. | Article | PubMed Abstract | PubMed FullText

66. Kemp AH, Quintana DS, Gray MA, Felmingham KL, Brown K and Gatt $J M$. Impact of depression and antidepressant treatment on heart rate variability: a review and meta-analysis. Biol Psychiatry. 2010; 67:106774. | Article | PubMed

67. Quintana DS, McGregor IS, Guastella AJ, Malhi GS and Kemp AH. A metaanalysis on the impact of alcohol dependence on short-term restingstate heart rate variability: implications for cardiovascular risk. Alcohol Clin Exp Res. 2013; 37 Suppl 1:E23-9. | Article | PubMed

68. Licht CM, de Geus EJ, van Dyck R and Penninx BW. Association between anxiety disorders and heart rate variability in The Netherlands Study of Depression and Anxiety (NESDA). Psychosom Med. 2009; 71:508-18. | Article | PubMed

69. Schumann A, Andrack C and Bar KJ. Differences of sympathetic and parasympathetic modulation in major depression. Prog Neuropsychopharmacol Biol Psychiatry. 2017; 79:324-331. | Article | PubMed

70. Kessinger R, Qualls T, Hart J, Dallies H, Anderson M, Wayland J and Bradshaw L. Pulse pressure findings following upper cervical care: a practice-based observational study. J Can Chiropr Assoc. 2019; 63:51-58. | PubMed Abstract | PubMed FullText

71. Win NN, Jorgensen AM, Chen YS and Haneline MT. Effects of Upper and Lower Cervical Spinal Manipulative Therapy on Blood Pressure and Heart Rate Variability in Volunteers and Patients With Neck Pain: A Randomized Controlled, Cross-Over, Preliminary Study. J Chiropr Med. 2015; 14:1-9. | Article | PubMed Abstract | PubMed FullText

72. Giles PD, Hensel KL, Pacchia CF and Smith ML. Suboccipital decompression enhances heart rate variability indices of cardiac control in healthy subjects. J Altern Complement Med. 2013; 19:92-6. | Article | PubMed Abstract | PubMed FullText

73. Bakris G, Dickholtz M, Sr., Meyer PM, Kravitz G, Avery E, Miller M, Brown $\mathrm{J}$, Woodfield $\mathrm{C}$ and Bell $\mathrm{B}$. Atlas vertebra realignment and achievement of arterial pressure goal in hypertensive patients: a pilot study. $\mathrm{J}$ Hum Hypertens. 2007; 21:347-52. | Article | PubMed

74. Torns S. Atlas vertebra realignment and arterial blood pressure regulation in 42 subjects. J Upper Cervical Chiropractic Res. 2012; 40-45.

75. Qualls T and Lester C. Resolution of atrial fibrillation and hypertension in a patient undergoing upper cervical Chiropractic Care. Journal of 
Kessinger et al, Neuroscience Discovery 2020,

http://www.hoajonline.com/journals/pdf/2052-6946-8-1.pdf

Upper Cervical Chiropractic Research. 2012; 1:9-15.

76. Burcon MT. Upper cervical specific pattern analysis utilizing paraspinal thermography, leg length inequality and heart rate variability in two patients with tachycardia. J Upper Cervical Chiropr Res. 2016; 1:6-12.

77. Kessinger RC, Anderson MF and Adlington J. Improvement in pattern analysis, heart rate variability \& symptoms following upper cervical chiropractic care. J Upper Cervical Chiropr Res. 2013; 2:32-42.

78. Knutson GA. Significant changes in systolic blood pressure post vectored upper cervical adjustment vs resting control groups: a possible effect of the cervicosympathetic and/or pressor reflex. J Manipulative Physiol Ther. 2001; 24:101-9. | Article | PubMed

79. Goodman R. Hypertension and the atlas subluxation complex. J Chiropr Res Clin Investigation. 1992; 8:30-32.

80. M.S. George, Z. Nahas, J.J. Borckardt, B. Anderson, M.J. Foust, C. Burns and S. Kose E.B. ShortBrain stimulation for the treatment of psychiatric disorders. Curr. Opin. Psychiatry. 2007; 20:250-254.

81. Daban C, Martinez-Aran A, Cruz N and Vieta E. Safety and efficacy of Vagus Nerve Stimulation in treatment-resistant depression. A systematic review. J Affect Disord. 2008; 110:1-15. | Article | PubMed

82. Rizvi SJ, Donovan M, Giacobbe P, Placenza F, Rotzinger S and Kennedy $\mathrm{SH}$. Neurostimulation therapies for treatment resistant depression: a focus on vagus nerve stimulation and deep brain stimulation. Int Rev Psychiatry. 2011; 23:424-36. | Article | PubMed

83. George MS, Sackeim HA, Rush AJ, Marangell LB, Nahas Z, Husain MM, Lisanby S, Burt T, Goldman J and Ballenger JC. Vagus nerve stimulation: a new tool for brain research and therapy. Biol Psychiatry. 2000; 47:28795. | Article | PubMed

84. Bonaz B, Sinniger $V$ and Pellissier $S$. The Vagus Nerve in the NeuroImmune Axis: Implications in the Pathology of the Gastrointestinal Tract. Front Immunol. 2017; 8:1452. | Article | PubMed Abstract | PubMed FullText

85. Miller $\mathrm{AH}$, Maletic $\mathrm{V}$ and Raison $\mathrm{CL}$. Inflammation and its discontents: the role of cytokines in the pathophysiology of major depression. Biol Psychiatry. 2009; 65:732-41. | Article | PubMed Abstract | PubMed FullText

86. Evrensel A and Ceylan ME. The Gut-Brain Axis: The Missing Link in Depression. Clin Psychopharmacol Neurosci. 2015; 13:239-44. | Article | PubMed Abstract | PubMed FullText

\section{Citation:}

Kessinger RC, Qualls T, Hart JF, Anderson MF, Dallies HJ, Wayland JM and Bradshaw BL. Depression and the craniocervical junction; a look at the hemispheric model. Neurosci Discov. 2020; 8:1.

http://dx.doi.org/10.7243/2052-6946-8-1 